\title{
SMALL-SCALE SEAWATER ELECTRODEIONIZATION
}

\author{
Khoiruddin Khoiruddin ${ }^{1}$, Ahmad Hakim ${ }^{1}$, Martin Bazant ${ }^{2}$, Mohammad Alkhadra ${ }^{2}$, and I. \\ Gede Wenten ${ }^{1}$ \\ ${ }^{1}$ Institut Teknologi Bandung \\ ${ }^{2} \mathrm{MIT}$
}

June 13, 2021

\begin{abstract}
In this work, the performance of electrodeionization (EDI) in seawater desalination was investigated. EDI stack design and operating parameters (applied voltage, recovery, and multi-stage process) were examined during a batch-mode desalination process. The results show that EDI can achieve $99.5 \%$ salt removal in a stack with $4 \mathrm{~mm}$ spacer thickness (at $20 \mathrm{~V}$ applied voltage, $75 \%$ recovery, and $2 \mathrm{~mL} / \mathrm{s}$ circulation flow rate). A thinner spacer thickness can enable a higher desalination rate and lower final solution temperature. Compared to a single-stage process, two-stage desalination can maintain the salt-removal rate, suppress reverse salt diffusion, and shorten the desalination time required to produce similar water quality. The specific energy consumption of EDI is below $12 \mathrm{kWh} / \mathrm{m} 3$ or less than $120 \mathrm{Wh}$ for producing $10 \mathrm{~L}$ freshwater. Considering its simplicity, EDI can be an attractive alternative for small-scale, decentralized desalination facilities.
\end{abstract}

\section{Hosted file}

Manuscript - AICHEJ - SWEDI.docx available at https://authorea.com/users/419634/articles/ 526070-small-scale-seawater-electrodeionization 
a

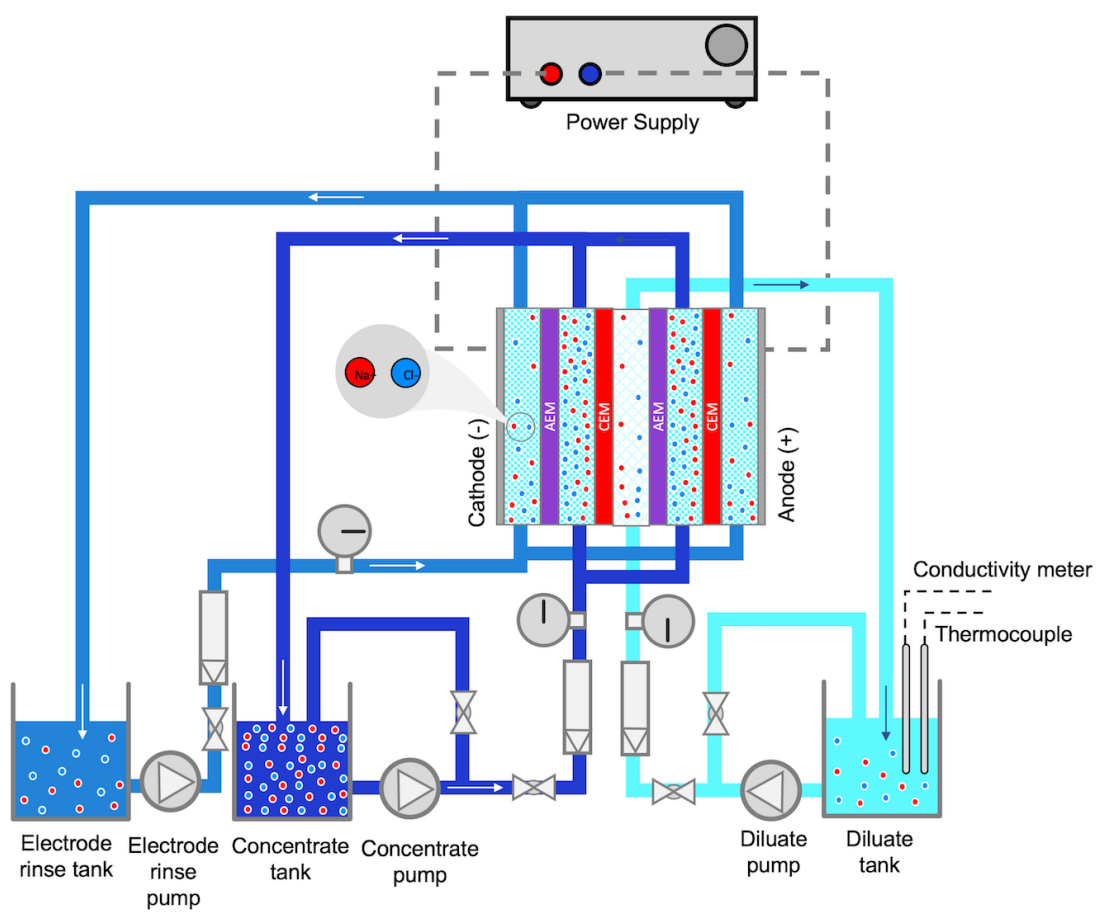

b

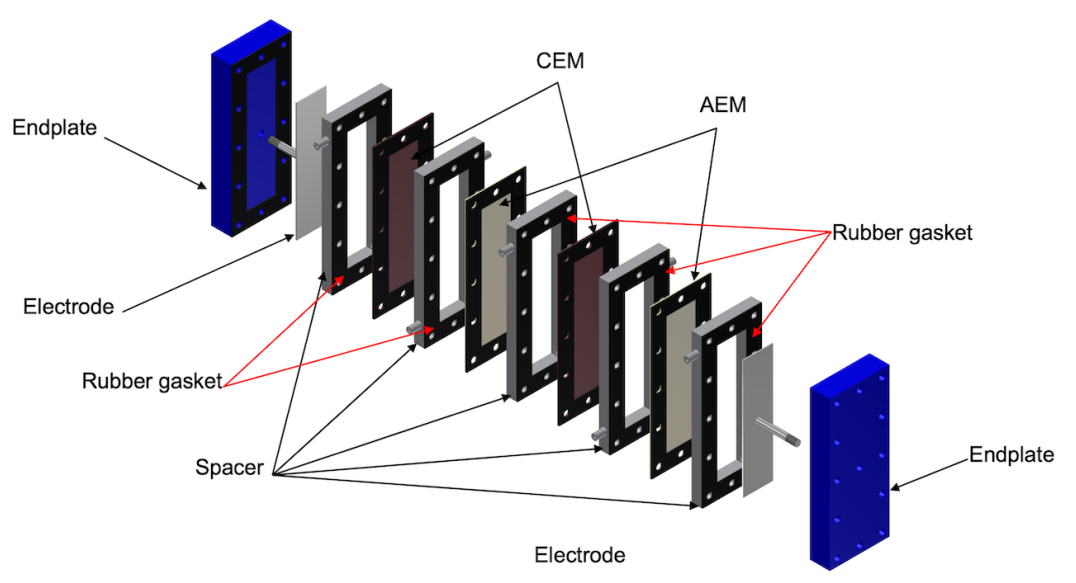



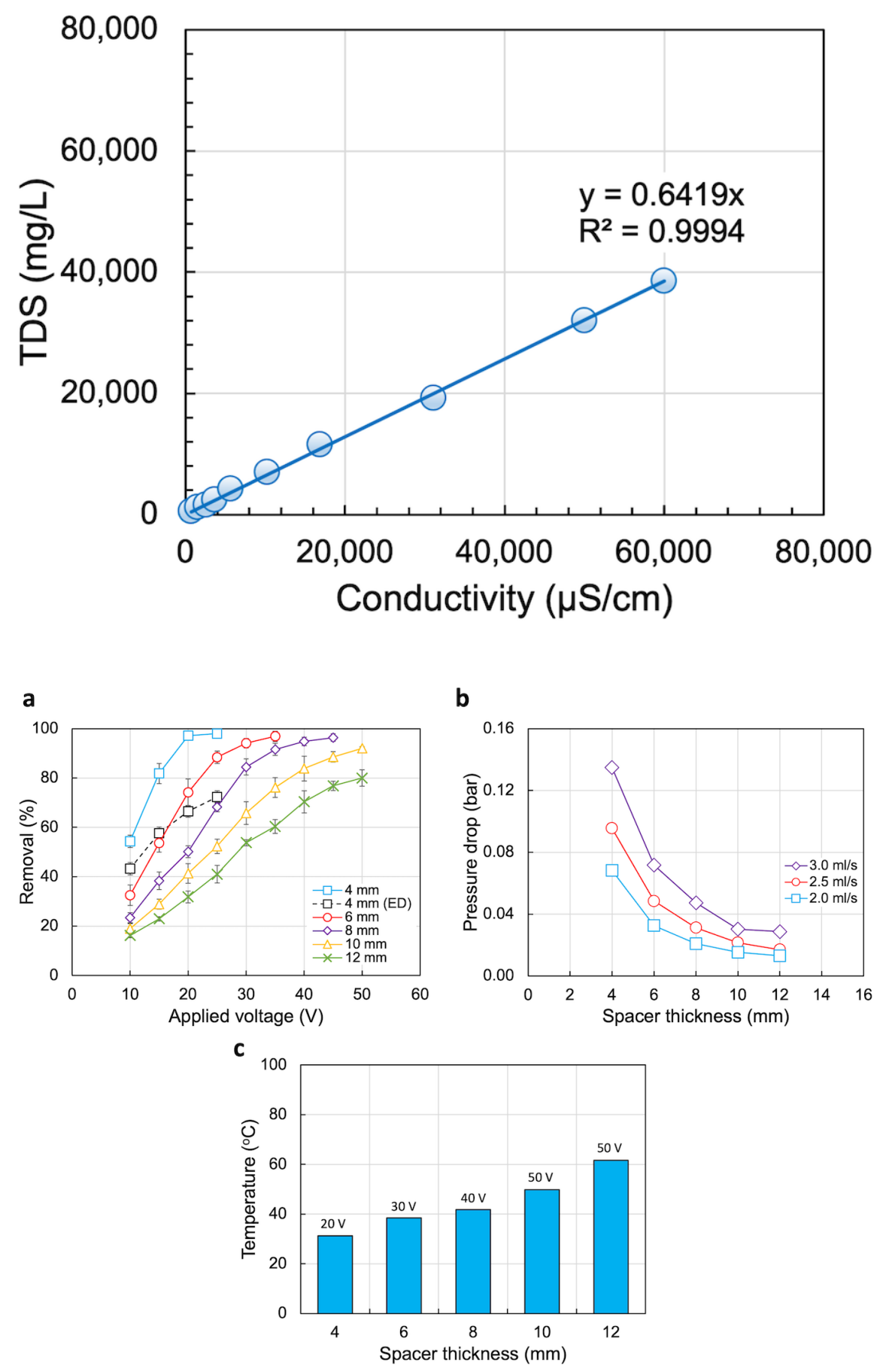


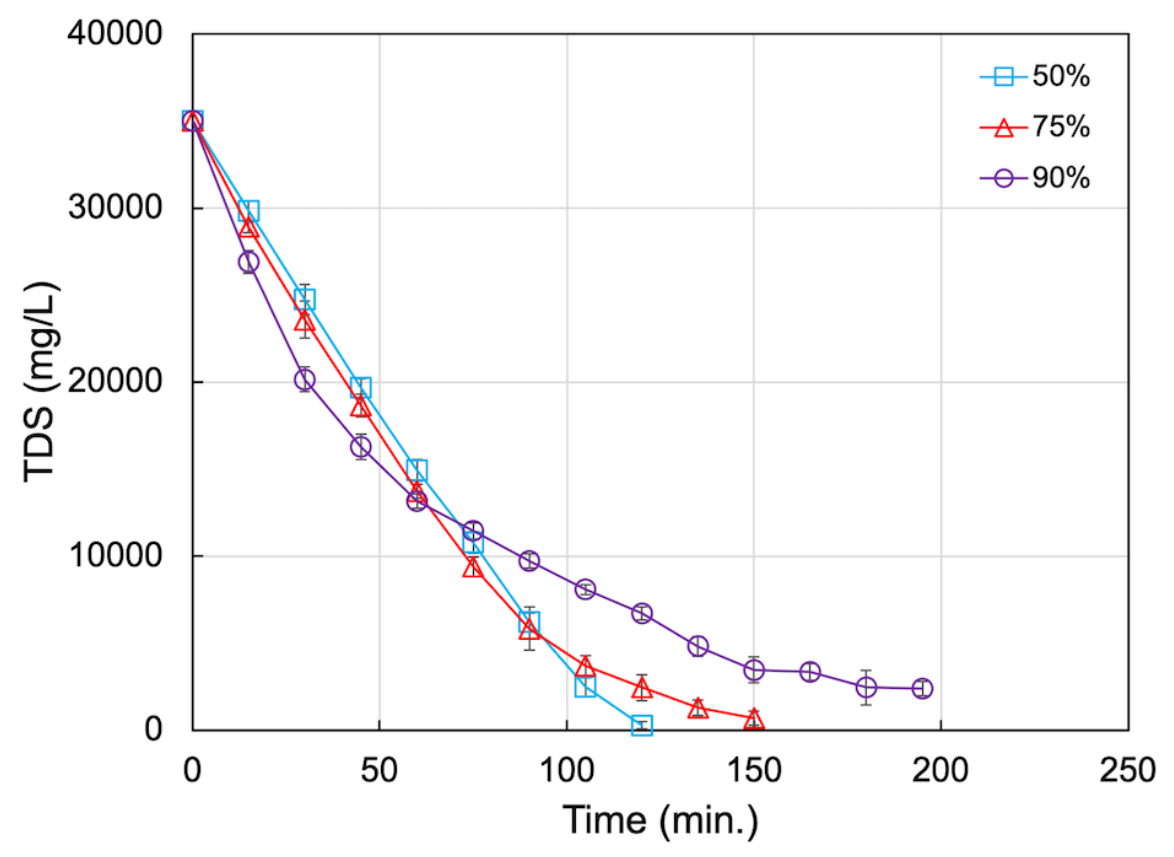

a

b
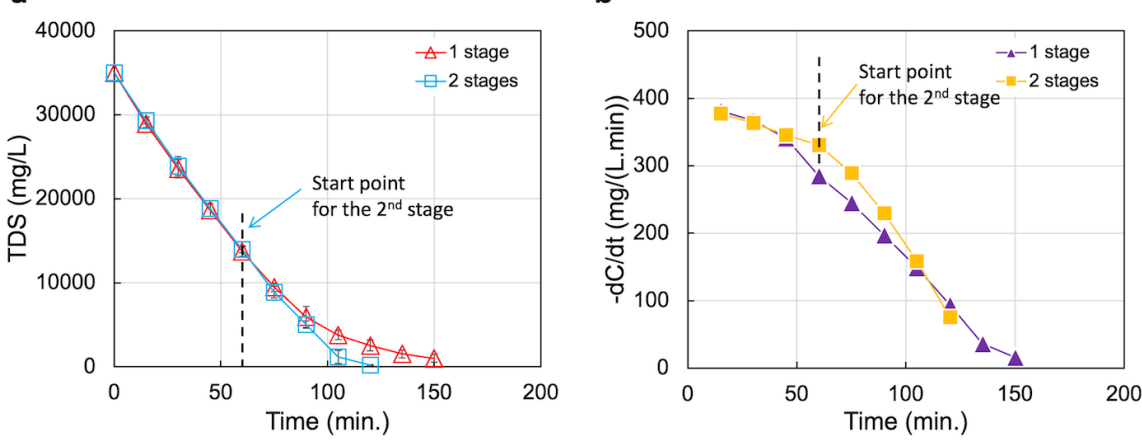


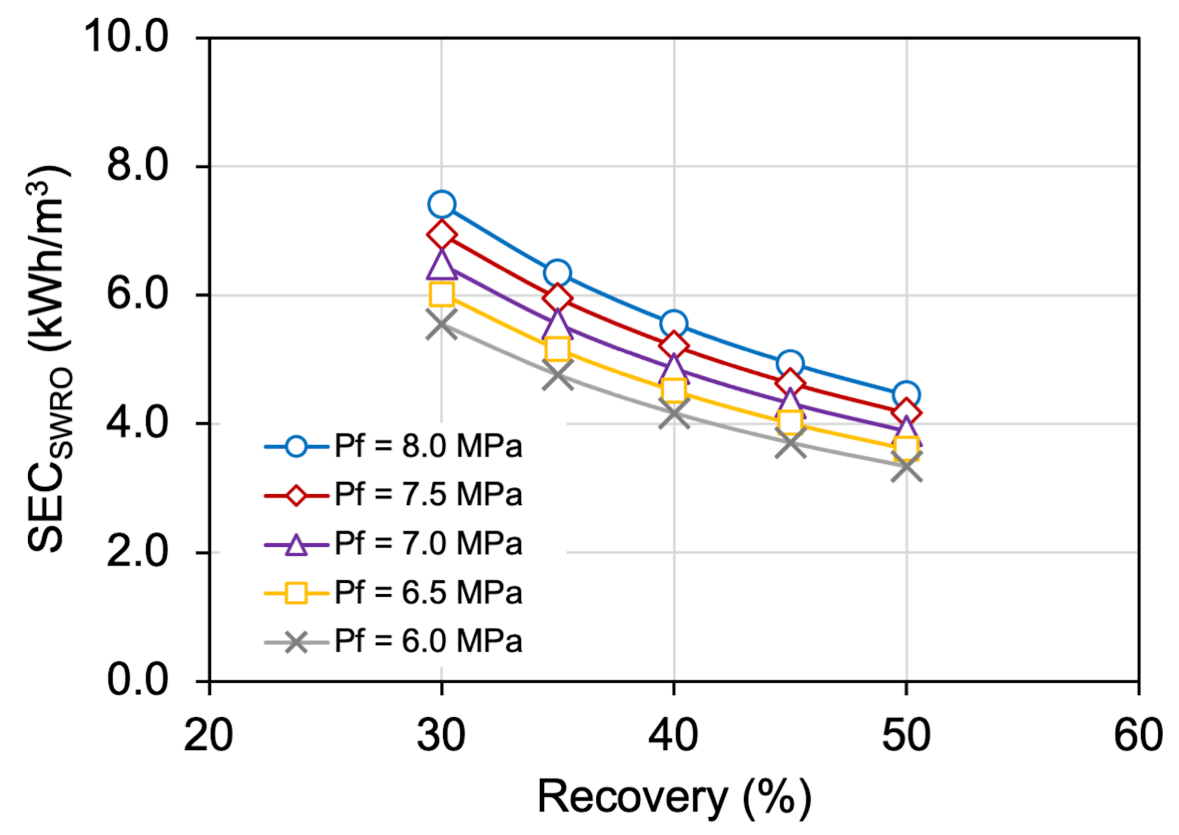

\section{Hosted file}

Tables - AICHEJ - SWEDI.docx available at https://authorea.com/users/419634/articles/526070small-scale-seawater-electrodeionization 